\title{
Enhanced induction of Bax gene expression in H460 and H1299 cells with the combined treatment of cisplatin and adenovirus mediated wt-p53 gene transfer
}

\author{
Ji Hyung Choi ${ }^{1}$, Kwang Sung Ahn², \\ Jhingook Kim ${ }^{3,4}$ and Young Sook Hong ${ }^{1,5}$ \\ ${ }^{1}$ Department of Biochemistry, College of Medicine, \\ Ewha Womans University, Seoul 158-056, Korea \\ ${ }^{2}$ Cancer Research Center, Center for Clinical Research, \\ Samsung Biomedical Research Institute, Seoul 135-230, Korea \\ ${ }^{3}$ Department of Thoracic Surgery, Samsung Medical Center, \\ College of Medicine, Sung Kyun Kwan University, \\ Seoul 135-230, Korea \\ ${ }^{4}$ Corresponding author: Tel, 82-2-3410-3483; Fax, 82-2-3410-0089; \\ E-mail: jkim@smc.samsung.co.kr \\ ${ }^{5}$ Corresponding author: Tel, 82-2-650-5725; Fax, 82-2-653-8891; \\ E-mail: yshong@mm.ewha.ac.kr
}

Accepted 10 June 2000

Abbreviations: Avp53, adenovirus mediated p53 gene transfer; ICE, interleukin-1 $\beta$-converting enzyme; wt-p53, wild type-p53

\begin{abstract}
Cytotoxic effect of either cisplatin or p53 gene transfection of lung cancer cells may be different depending on the p53 status of cells. We investigated cytotoxic effects on the combined treatment of cisplatin and adenovirus mediated p53 gene transfer (Avp53) in both $\mathrm{H} 460$ and $\mathrm{H} 1299$ cells in vitro. The results showed the highest numbers of apoptotic cells in both $\mathrm{H} 460$ and $\mathrm{H} 1299$ cells following the combined treatment regardless of p53 status in comparison with either cisplatin or Avp53 alone. The expression levels of p53, p21, Bax and ICE were examined to understand a possible cellular signal path of the combined treatment. In western analyses, the patterns of phosphorylated p53 protein were different between Avp53 and combined treatment. The expressions of p21 and Bax were increased in combined treatment, whereas the cleaved form of ICE (20 kD) was not detected. These results suggest that cisplatin induced p53 protein phosphorylation and may activate the downstream of p53 gene expression such as p21 and Bax. The enhanced apoptosis of lung cancer cells by the combined treatment may be useful in the development of clinical therapeutic modality of lung tumors.
\end{abstract}

Keywords: apoptosis, Avp53, Bax, cisplatin, combined treatment

\section{Introduction}

Cisplatin-based chemotherapy has been frequently used for an advanced lung cancer. Induction of p53 expression in lung cancer cells treated with cisplatin triggers apoptotic pathway. The p53 gene is an essential component of the pathway leading to two different critical functions: G1 growth arrest and apoptosis (Hale et al., 1991; Levine, 1997). When p53 is expressed in cancer cells, it has to be phophorylated in order to induce expressions of the downstream of p53 genes such as p21 and Bax. The expressions of p21 and Bax induce the apoptotic pathways. (Haapajarvi et al., 1999). Cisplatin could induce apoptosis via p53 independent apoptotic pathway in cancer cells with alterations of p53 (Wang et al., 1997). There are some evidences showing that the cytotoxic effect of cisplatin in cancer cells may be related to ICE and CPP32 (Chen et al., 1996; Eichh-oltz et al., 1997). Recently, several studies have shown that mutant or null p53 have been responsible for the failure of lung cancer to respond to chemotherapy (Lowe et al., 1993; Rusch et al., 1995; Muller and Eppenberger, 1996). To overcome the difficulties in cisplatin treatment of lung cancer cells with alteration of p53, p53 gene therapy, as an alternative method, has been introduced. But as shown in previous data, the cytotoxic effect of Avp53 also depends on p53 status of lung cancer cells (Kim et al., 1997). We concluded that cytotoxic effect of either cisplatin or Avp53 treatment depends on the status of $\mathrm{p} 53$.

Since cytotoxic effects of both cisplatin and Avp53 were different depending on the status of $p 53$, we needed to design different methods for lung cancer regardless of p53 status. In lung cancer cells expressing wt-p53, cisplatin was sensitive but Avp53 was resistant. Whereas, Avp53 was more effective in lung cancer cells without wt-p53 expression than those with wt-p53 expression. Based on the above concepts, combined treatment with cisplatin and Avp53 may enhance the cytotoxic effect regardless of p53 status and it would increase the survival rate of lung cancer patients. Nguyen et al., reported that p53 gene therapy for lung cancer using the sequential combination of cisplatin administration and adenovirus mediated p53 gene transfer had led to enhance suppression of tumor growth and apoptosis. However, the mechanism still remains unknown. In this study, we design- 
ed the methods of combined treatment in vitro. Subsequently the cytotoxic effect was examined in $\mathrm{H} 460$ cells expressing wt-p53 and $\mathrm{H} 1299$ cells having null p53 in lung cancer. To investigate the mechanism of apoptosis resulted from combined treatment in H1299 cells, we also analyzed the expression of apoptosis related genes, such as p21, Bax and ICE.

\section{Materials and Methods}

\section{Cell culture and adenovirus mediated wt-p53 gene}

The human NSCLC cell lines H460; wt-p53, H1299; a homozygous deleted were obtained from the American Type Culture Collection (Rockville, MD). Cell lines were maintained at $37^{\circ} \mathrm{C}$ in $5 \% \mathrm{CO}_{2}$ in RPMl-1640 (Biowhittaker, Walkersville, MD) supplemented with $10 \%$ fetal bovine serum (FBS) and 1\% penicillin-streptomycin (GibcoBRL, Gland island, NY). The construction of a recombinant adenoviral vector containing cDNA encoding human wt-p53 was kindly provided by Dr. Je ho Lee (Department of Obstetrics and Gynecology, Samsung Medical Center, Korea). Cisplatin was obtained from Dong-A Pharmaceutical Co. Ltd (Seoul, Korea).

\section{MTT assay for cytotoxicity}

The cytotoxicities of cisplatin, Avp53, and combination of both on lung cancer cells were analyzed by MTT assay as described previously (Kim et al., 1997). Cells $\left(1 \times 10^{3}\right)$ were seeded in each well of 96 -well microtiter plates. Three different methods used in this study are as follow: treatment with cisplatin alone; cells were treated with $25 \mu \mathrm{g} / \mathrm{ml}$ cisplatin for $1 \mathrm{~h}$ and then replaced with new medium. Avp53 infection alone; cells were infected with 2 moi Avp53 for $1 \mathrm{~h}$, new medium was added and incubated. Combined treatment (cisplatin and Avp53); Avp53 was subjected to cell pretreatment with cisplatin for $1 \mathrm{~h}$. After new RPMI-1640 medium supplemented with $10 \%$, FBS was added and incubated. After $48 \mathrm{~h}$, all of cells were analyzed using MTT assay as follows: MTT solution $50 \mu \mathrm{l}(5 \mathrm{mg} / \mathrm{ml}$ Sigma Chemical Co., St Louis, MO) in PBS was added to each well, and then incubated for $4 \mathrm{~h}$ at $37^{\circ} \mathrm{C}$. The formazan crystals were dissolved in $50 \mu \mathrm{l}$ of dimethyl sulfoxide (DMSO, Amre-sco, Solon, Ohio). The optimal density was determined with microculture plate reader (Becton Dickinson Labware, Lincoln Park, NJ) at $540 \mathrm{~nm}$. Absorbance values were normalized to the values obtained for control to determine the value for \% of survival. Each assay was performed in triplicate. $\mathrm{IC}_{50}(50 \%$ Inhibitory Concentration) value was drug concentrations inducing a $50 \%$ reduction in the optical density.

\section{Northern blot analysis}

Total RNA was prepared using TRIzol (GibcoBRL, Gland island, NY) according to manufacturer's instructions. Total RNA $(10 \mu \mathrm{g})$ from each sample was electrophoresed on $1 \%$ agarose containing $2.2 \mathrm{M}$ formaldehyde, transferred to a $\mathrm{H}$-bond nitrocellulose membrane (Amersham, Buckinghamshire, UK), and hybridized for $24 \mathrm{~h}$ at $42^{\circ} \mathrm{C}$ to Bax cDNA probes radio-labeled by random primer extension with $\left[\alpha{ }^{32} \mathrm{P}\right] \mathrm{dCTP}$. $\beta$-actin probe was used to confirm approximately equal loading of total RNA in all tracts. The blots were washed twice for $30 \mathrm{~min}$ at $42^{\circ} \mathrm{C}$ with $2 \times$ SCC containing $0.1 \%$ SDS and then for $30 \mathrm{~min}$ at $42^{\circ} \mathrm{C}$ with $0.2 \times$ SCC containing $0.1 \%$ SDS. The blots were exposed for $48 \mathrm{~h}$ at $-70^{\circ} \mathrm{C}$.

\section{Western blot analysis}

Cells were lysed in RIPA buffer (50 mM Tris- $\mathrm{HCl}$ (pH 8.0), $150 \mathrm{mM} \mathrm{NaCl}, 1 \%$ NP40, 0.1\% SDS, 10 mM Sodium deoxycholate). Protein lysates $(30 \mu \mathrm{g})$ from each sample were electrophoresed on a $12 \%$ SDS-polyacrylamide gel and were then transferred to a nitrocellulose membrane (Amersham, Buckinghamshire, UK) with a constant of $50 \mathrm{~V}$ for $3 \mathrm{~h}$. Membranes were preblocked for $2 \mathrm{~h}$ at room temperature in TTBS (Tris-buffered saline containing $0.005 \%$ Tween 20 ) containing $5 \%$ skim milk powder. Blots were incubated overnight at $4^{\circ} \mathrm{C}$ with a 1:500diluted monoclonal antibody to human p53 (Novocastra, Newcastle upon Tyne, UK), human Bax (Santa Cruz, CA), and human ICE (Santa Cruz, CA)in TTBS. The blots were washed 3 times for 15 min each time with TTBS. The membranes were then incubated for $1 \mathrm{~h}$ with horseradish peroxidase-conjugated anti-mouse IgG antibody (Amersham, Buckinghamshire, UK) for anti-p53 antibody, anti-rabbit IgG antibody (Amersham, Buckinghamshire, UK) for anti-Bax and anti-gout IgG antibody (Santa Cruz, CA) for anti-ICE. The blots were washed 3 times for $15 \mathrm{~min}$ each time with TTBS. Proteins were detected using an enhanced chemiluminescence western blot analysis system (Amersham, Buckinghamshire, UK).

\section{Acridine orange staining for apoptotic cells}

Cells were harvested by trypsinization and washed in PBS (phosphate-buffered saline). After several washings, cells were centrifuged and resuspended in fixation solution ( $75 \%$ methanol and $25 \%$ glacial acetic acid) for $30 \mathrm{~min}$ in ice (Badie et al., 1999). Fixed cells were washed twice in PBS and stained $0.1 \%$ acridine orange in PBS (Sigma Chemical Co, St. Louis, MO). Stained cells were washed in PBS and visualized under a fluorescent microscope $(\times 100$, BX50, Olympus, Japan).

\section{Statistics}

Statistical analysis was performed using Student's t-test for differences between groups. Statistical significance was defined as $\mathrm{p}<0.05$. 


\section{Results}

\section{Cytotoxic effect of cisplatin in lung cancer cells in vitro}

To investigate the role of p53 for cisplatin-treated lung cancer cells, we examined the cytotoxicity of cisplatin in H460 cells expressing wt-p53 and H1299 cells having null p53. As shown in Figure 1, cells treated with cisplatin from 1 to $100 \mu \mathrm{g} / \mathrm{ml}$ concentrations for $48 \mathrm{~h}$ exhibited viability of $97 \sim 34 \%$ in $\mathrm{H} 460$ cells and $99 \sim 69 \%$ in $\mathrm{H} 1299$ cells, respectively. $\mathrm{H} 460$ cells were more sensitive to cisplatin than $\mathrm{H} 1299$ cells suggesting that the overexpression of p53 by cisplatin treatment could lead to apoptotic pathways. Reports of cytotoxic effects induced by adenovirus mediated wt-p53 gene transfection of lung cancer cells suggested that the expres-

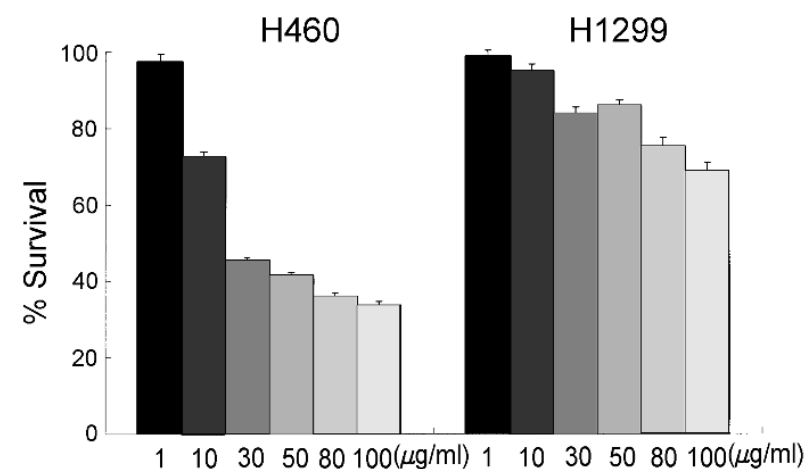

Figure 1. Anti-tumor effects of cisplatin on the growth of $\mathrm{H} 460$ and $\mathrm{H} 1299$ lung cancer cells. Both cells were treated with various concentration of cisplatin $(\mu \mathrm{g} / \mathrm{ml})$ for $1 \mathrm{~h}$ and then replaced with new RPMl-1640 medium supplemented with $10 \%$ FBS. The rate of cellular survival was measured using MTT assay after incubation for $48 \mathrm{~h}$. In overall survival rate, $\mathrm{H} 460$ cells were more sensitive to cisplatin than $\mathrm{H} 1299$ cells. Data are the means \pm standard deviations of triplicate samples. Student's t-test value was less than 0.05 .

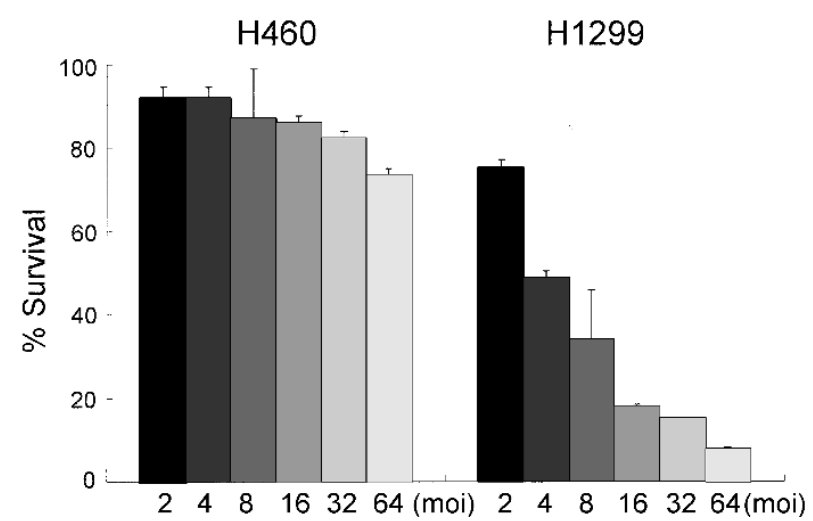

Figure 2. Anti-tumor effects of Avp53 on the growth of $\mathrm{H} 460$ and $\mathrm{H} 1299$ lung cancer cells. Both cells were infected with various concentration of Avp53 (moi, multiplicity of infection) for $1 \mathrm{~h}$. After incubation, new RPMl1640 medium supplemented with 10\% FBS was added and incubated for $48 \mathrm{~h}$. At $48 \mathrm{~h}$, the cellular survival rate was measured using MTT assay. Overall survival rate revealed that $\mathrm{H} 460$ cells were higher than $\mathrm{H} 1299$ cells. Data are the means \pm standard deviations of triplicate samples. Student's ttest value was less than 0.05 . sion of wt-p53 gene in lung cancer could have played one of critical roles in inducing the cytotoxic effect of cisplatin. As shown in Figure 2, cells transfected with increasing concentrations of Avp53 from 2 to 64 moi for $48 \mathrm{~h}$ showed viabilities of 91 to $73 \%$ in $\mathrm{H} 460$ cells and 75 to $8 \%$ in $\mathrm{H} 1299$ cells, respectively. These results revealed that $\mathrm{H} 1299$ cells were more sensitive to Avp53 and were different from the cytotoxic effect of cisplatin.

\section{Cytotoxic effect of combined treatment in lung cancer cells in vitro}

To explore a possible method to enhance the induction of the cytotoxic effect of cisplatin in lung cancer cells without depending on p53 status, we tested combined treatment in both $\mathrm{H} 460$ and $\mathrm{H} 1299$ cells. As shown in Figure 3, both cells incubated with cisplatin for $1 \mathrm{~h}$, then treated with Avp53 for $48 \mathrm{~h}$ showed greater cytotoxicity than either with cisplatin or Avp53 treatment alone. $\mathrm{H} 460$ cells with combined treatment showed $20 \%$ and $50 \%$ greater inhibition of cell proliferation. Also, the inhibition of $\mathrm{H} 1299$ cell proliferation was also significantly higher (50\% of cisplatin and $30 \%$ of Avp53 treatment alone) with combined treatment. Cellular sensitivity of $\mathrm{H} 460$ and $\mathrm{H} 1299$ cells in the combined treatment was rather similar. To confirm the inhibition of cell proliferation, apoptotic cells were examined using acridine orange staining. The results showed that apoptotic cells were significantly higher in cells with the combined treatment among four groups (Table 1). As shown in Figure 4, the nuclear fragmented cells were detected in combined treatment group in comparison to other three groups

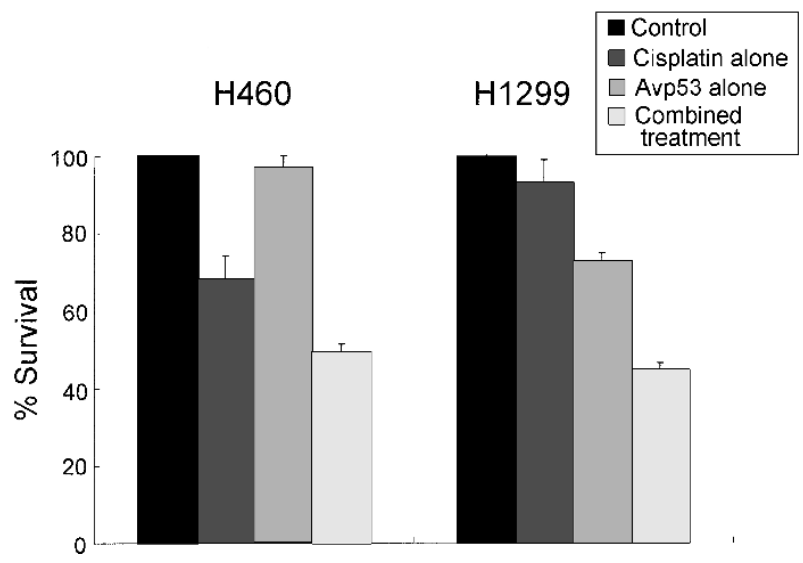

Figure 3. Anti-tumor effects of combined treatment on the growth of $\mathrm{H} 460$ and H1299 lung cancer cells. Cisplatin and Avp53 treatments, respectively was used as described in materials and methods. In combined treatment, the cells were treated with $25 \mu \mathrm{g} / \mathrm{ml}$ cisplatin for $1 \mathrm{~h}$, washed with new medium and then infected with 2 moi Avp53 for $1 \mathrm{~h}$. New RPMl-1640 medium supplemented with $10 \%$ FBS was added and incubated. At $48 \mathrm{~h}$, the rate of cellular survival was measured using MTT assay. Overall survival rate revealed that the cytotoxicity of combined treatment was more effective than either cisplatin or Avp53 alone treatment in both cells. Data are the means \pm standard deviations of triplicate samples. Student's t-test value was less than 0.05 . 
Table 1. Apoptotic Index. After stained with $0.1 \%$ of acridine orange, cells with nuclear fragmentations were counted under a fluorescent microscopy $(\times 100)$. The nuclear fragmentation is one of characteristics of apoptotic cells. This experiment was carried out three times and data are the sum of 3 experiments

\begin{tabular}{lcccccccc}
\hline & \multicolumn{2}{c}{ Control } & \multicolumn{2}{c}{ Cisplatin alone } & \multicolumn{2}{c}{ Avp53 alone } & \multicolumn{2}{c}{ Combined treatment } \\
\cline { 2 - 9 } & $\mathrm{H} 460$ & $\mathrm{H} 1299$ & $\mathrm{H} 460$ & $\mathrm{H} 1299$ & $\mathrm{H} 460$ & $\mathrm{H} 1299$ & $\mathrm{H} 460^{*}$ & $\mathrm{H} 1299^{*}$ \\
\hline Cancer cells & 148 & 146 & 86 & 128 & 141 & 91 & 43 & 37 \\
Apoptotic cells & 2 & 4 & 64 & 22 & 9 & 59 & 107 & 113 \\
\% of Apoptosis & $1.3 \%$ & $2.7 \%$ & $42.6 \%$ & $14.7 \%$ & $6.0 \%$ & $39.3 \%$ & $71.3 \%$ & $75.3 \%$ \\
& $( \pm 1.4)$ & $( \pm 1.4)$ & $( \pm 3.4)$ & $( \pm 2.7)$ & $( \pm 2.0)$ & $( \pm 5.4)$ & $( \pm 4.0)$ & $( \pm 6.0)$ \\
\hline
\end{tabular}

*indicates that the value is statistically significant $(p<0.05)$

H460
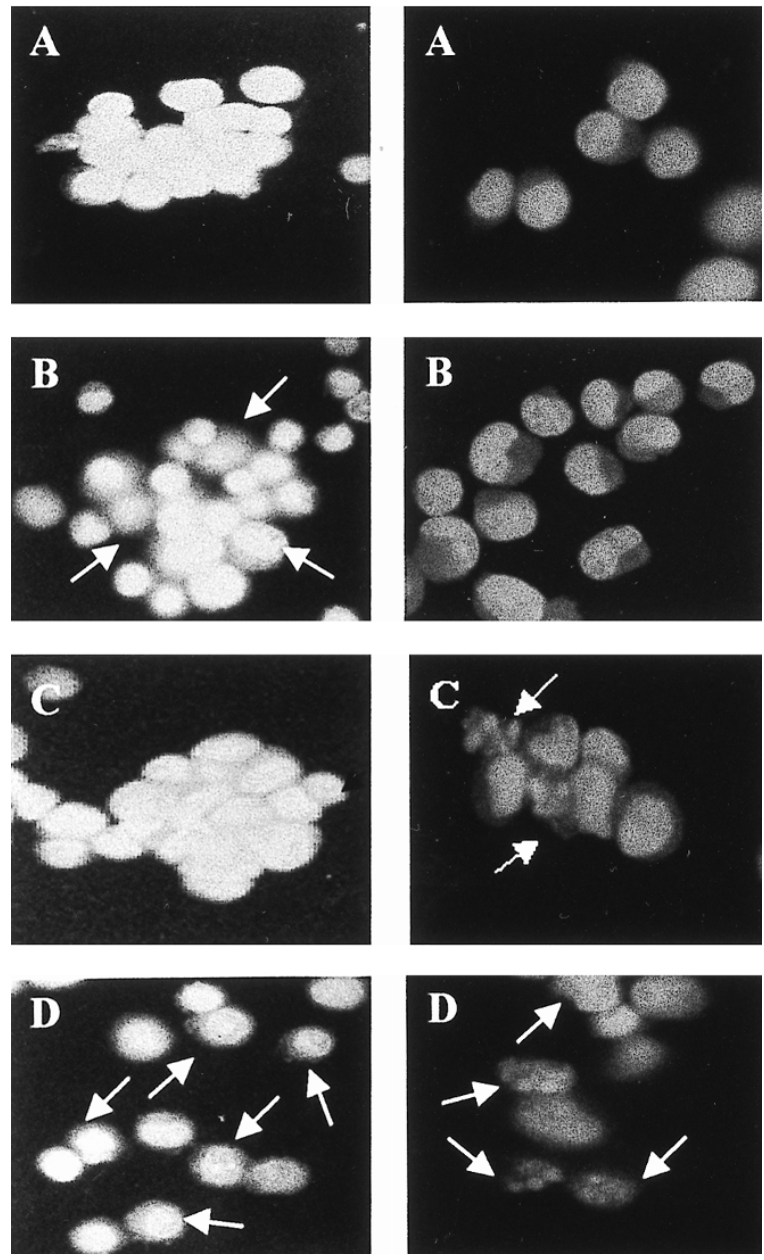

Figure 4. Morphological analysis of $\mathrm{H} 460$ and $\mathrm{H} 1299$ lung cancer cells in various treatments. Cisplatin and Avp53 treatments, respectively was subjected as described in materials and methods. In combined treatment, the cells were treated with $25 \mu \mathrm{g} / \mathrm{ml}$ cisplatin for $1 \mathrm{~h}$, washed with new medium and then infected with 2 moi Avp53 for $1 \mathrm{~h}$. After new RPMI-1640 medium supplemented with 10\% FBS was added, cells were incubated for $48 \mathrm{~h}$. Cells were stained with acridine orange and analyzed under a fluorescence microscope $(\times 100)$. A, control; B, cisplatin alone; C, Avp53 alone; $D$, combined treatment.

and its cytotoxic effect was significantly increased regardless of p53 status.

\section{Investigation of mechanism conferring apoptosis by combined treatment}

Recently, the cytotoxic effect of cisplatin was linked to the expression of proto-oncogenes or tumor suppressor genes such as p53 and Bax. However, cells expressing wt-p53 gene undergo apoptosis. To examine the effects of combined treatment, we tested the expression of genes related to both p53 dependent and independent apoptotic pathways. In northern analyses, the expression of Bax gene was increased when $\mathrm{H} 1299$ cells were treated with both cisplatin and Avp53 (Figure 5). The increasing levels of Bax gene expression in combined treatment as compared to Avp53, may be derived from cisplatin treatment. The expression levels of Bax gene were normalized using $\beta$-actin. As shown in Figure 6A, the expression of p53 was detected in both cells treated with Avp53 but not in control cells and cells treated with cisplatin. The patterns of phosphorylated p53 protein were different between cells treated with Avp53 and combined treatment. The expressions of p21 and Bax proteins were increased in combined treatment (Figure 6). However, the cleaved forms of ICE were not detected in cells whereas transcripts were slightly increased (Figure 6).

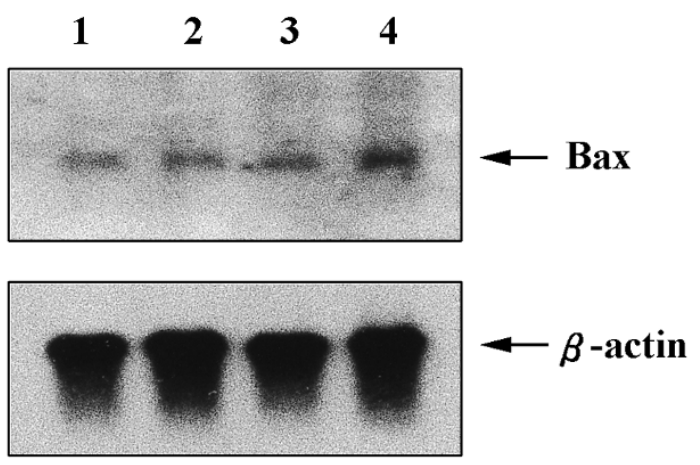

Figure 5. Analyses for expression of bax gene in various treatments for H1299 cells. H1299 cells were treated with cisplatin $(25 \mu \mathrm{g} / \mathrm{ml})$ and Avp53 (2 moi), respectively as described in materials and methods. In combined treatment, the cells were treated with $25 \mu \mathrm{g} / \mathrm{ml}$ cisplatin for $1 \mathrm{~h}$, washed with new medium and then infected with 2 moi Avp53 for $1 \mathrm{~h}$. After incubation, new RPMI-1640 medium supplemented with $10 \%$ FBS was added, cells were incubated for $4 \mathrm{~h}$. Total RNA $(10 \mu \mathrm{g})$ was used for northern blot analysis. $\beta$-actin probe was used to normalize amounts of total RNA in each lane. Lane 1; control, Lane 2; cisplatin alone, Lane 3; Avp53 alone, Lane 4; combined treatment. 

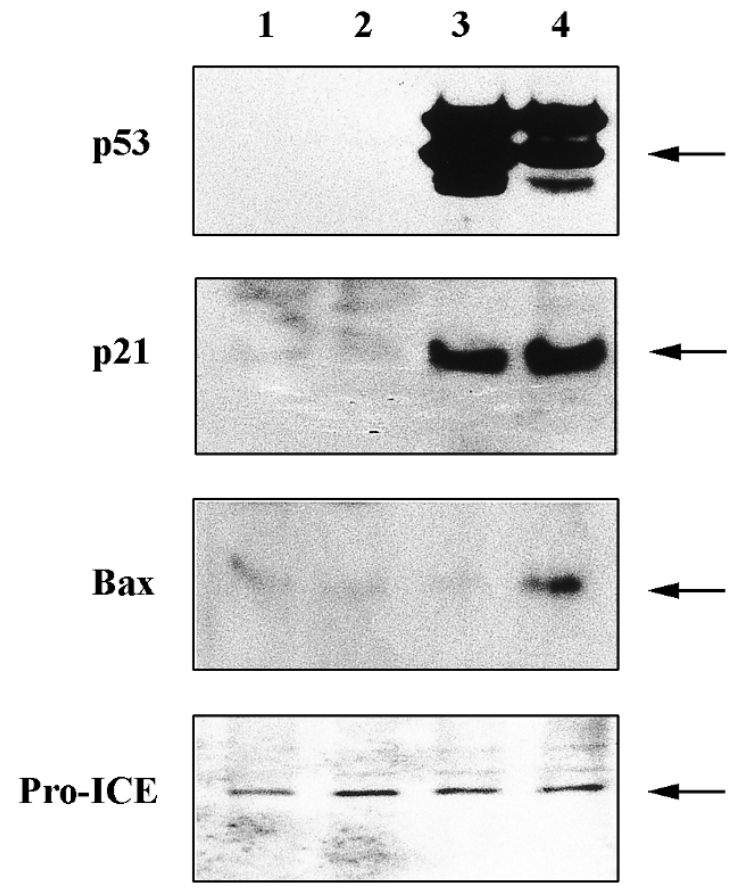

Figure 6. Analyses for expression of p53, p21, Bax and ICE protein in various treatments for $\mathrm{H} 1299$ cells. $\mathrm{H} 1299$ cells were treated as described in materials and methods. In combined treatment, the cells were treated with $25 \mu \mathrm{g} / \mathrm{ml}$ cisplatin for $1 \mathrm{~h}$, washed with new medium and then infected with 2 moi Avp53 for $1 \mathrm{~h}$. After new RPMl-1640 medium supplemented with 10\% FBS was added, cells were incubated for $4 \mathrm{~h}$. The lysates of $\mathrm{H} 1299$ cells were provided using RIPA buffer and the lysates $(30 \mu \mathrm{g})$ were then used for western blot analysis. Lane 1; control, Lane 2; cisplatin alone, Lane 3; Avp53 alone, Lane 4; combined treatment.

\section{Discussion}

Cisplatin-based chemotherapy has been largely used for aggressive lung cancer. Successful outcome of this treatment could not be obtained because alterations of p53 gene prevent from increasing the activity of cisplatin in lung cancer. Cisplatin, as a DNA damaging agent, could not only induce the expression of p53 gene but also lead to programmed cell death. The p53 protein is a sequence-specific transcription factor that plays an important role in coupling DNA damage to growth arrest and/or the apoptotic response of a cell with DNA damage (Hale et al., 1991; Levine, 1997). The most of the cellular activity by cisplatin underlies p53 dependent apoptotic pathway (Anne et al., 1996; Michael, 1998). Whereas, the cellular activities by cisplatin in lung cancer cells with alterations of p53 gene may rely on the p53 independent apoptotic pathway. There are multiple mechanisms that contribute to cytotoxic effect of cisplatin; These include activated genes related to the p53dependent and -independent apoptotic pathways. Consequently, the success of cisplatin-based chemotherapy could not be expected since alterations of p53 gene have been found in more than $70 \%$ of lung cancer.
Many studies have shown that cancer cells may show different cytotoxic responses at the same levels of DNA damage depending on the status of p53 (Lowe et al., 1993; Muller and Eppenberger, 1996).

Many studies have shown that Avp53 induced apoptosis in vitro (Fujiwara et al.,1994; Ogawa et al., 1997; Mikhail et al., 1998) and inhibit tumor growth in vivo (Nguyen et al., 1996) in cancer cells expressing mutated p53 and having null p53. Even though some of studies showed the apoptosis by Avp53, suppression of tumor growth was not achieved completely. To understand the cytotoxic effect of either Avp53 or cisplatin, two lung cancer cell lines ( $\mathrm{H} 460$ and $\mathrm{H} 1299)$ with variable p53 activities were selected. Our study revealed that $\mathrm{H} 460$ cells expressing wt-p53 were more sensitive to cisplatin than $\mathrm{H} 1299$ cells having null p53, whereas the responses to Avp53 were the opposite.

These observations were consistent with those reported previously (Kim et al., 1997). In this study, we selected the null p53 lung cancer cell line and tested a possibility that overexpression of p53 may produce synergic cytotoxic effects of $\mathrm{H} 1299$ cells that are insensitive to cisplatin. Also, we investigated the mechanism of apoptosis in combined therapy. Cellular apoptosis was induced by p53-independent pathway without p53 expression and it may involve the activation of ICE and CPP32 (Chen et al., 1996; Eichholtz et al., 1997). However, we were not able to find the cleavage form of ICE in cells with combined treatment.

Araki et al. reported that an enhanced phosphorylation of p53 not only increases the cytotoxic effects but also arrests cell cycles in DNA damaged cells. We also found that the patterns of phosphorylated p53 were different. In addition, the expressions of p21 and Bax were dramatically increased in combined treatment. These findings demonstrate that changes in the pattern of p53 phosphorylation may be strongly related to induction of p21 and Bax. p53 protein has to be phosphorylated in order to induce functional protein of p53 downstream pathway such as Bax (Annette et al., 1996). We suggest that cisplatin, active DNA dependent protein kinases and those activations may regulate the phosphorylation of p53. In agreement with this observation, Perego et al. demonstrated that the level of expression of Bax mRNA was higher in IGROV-1 ovarian carcinoma cells that expressed a transcriptionally active p53. The molecules such as Bax act downstream of DNA damage to modulate the threshold undergoing apoptotic cell death. Notably, Bax, a proap-optotic member of the Bcl-2 family, has also been shown to be a transcriptional target of p53 in some cell types (Miyashita et al., 1994; Aristides et al., 1995). Consistent with the role of Bax in increasing the sensitivity of cells to chemotherapeutic agents, $\mathrm{H} 1299$ lung cancer cells with combined treatment were shown to increase Bax expression and resulted in apoptosis. We conclude that sequential cisplatin and Avp53 combined 
treatment, in vitro, may lead to synergic effects of apoptosis by increasing the expression of p21 and Bax gene resulted from phosphorylated p53 after introduction of cisplatin into the cells.

\section{Acknowledgment}

The construction of a recombinant adenoviral vector containing cDNA,encoding human wt-p53 was kindly provided by Dr. Je Ho Lee (Department of Obstetrics and Gynecology, Samsung Medical Center, Korea). This work is supported by the Samsung grant, \#SBRI C99010-1.

\section{References}

Anne, F., Jacqueline, D. S., Jean, C. A., Jean, G. R. Jean, F. B., Guy, R. and Jean, B. (1996) Cisplatin-induced apoptosis and p53 gene status in a cisplatin-resistant human ovarian carcinoma cell line. Int. J. Caner. 68: 67-74

Annette, J. H., Christopher, A. S., Leslie, C. S., Victoria, E. A. S., Vanessa, L. L., Aedin, C. C. and Gwyn, T. W. (1996) Apoptosis: molecular regulation of cell death. Eur. J. Biochem. 236: 1-26

Araki, R., Fukumura, R., Fujimori, A., Taya, Y., Shiloh, Y., Kurimasa, A., Burma, S., Li, G. C., Chen, D. J., Sato, K., Hoki, Y., Tatsumi, K. and Abe, M. (1999) Enhanced phosphorylation of p53 serine 18 following DNA damage in DNA-dependent protein kinase catalytic subunit-deficinet cells. Cancer Res. 59: 3543-3546

Aristides, G. E., David, J. K., Jonathan, H., Liz, H., Stanislaw, K., John, C. R. and Lawrence, S. Y. (1995) The control of apoptosis and drug resistance in ovarian cancer: influence of p53 and Bcl-2. Oncogene. 11: 1217-1228

Badie, B., Goh, C. S., Klaver, J., Herweijer, H. and Boothman, D. A. (1999) Combined radiation and p53 gene therapy of malignant glioma cells. Cancer Gene Therapy. 6: 155-162

Chen, Z., Naito, M., Mashima, T. and Tsuruo, T. (1996) Activation of actin-cleavable interleukin 1beta-converting enzyme (ICE) family protease CPP-32 during chemotherapeutic agent-induced apoptosis in ovarian carcinoma cells. Cancer Res. 56: 5224-9

Eichholtz, W. H., Stoetzer, O. and Marx, K. (1997) Reduced expression of the ICE-related protease CPP32 is associated with radiation-induced cisplatin resistance in HeLa cells. Br. J. Cancer. 76: 1322-7

Fujiwara, T., Grimm, E. A., Mukhopadhyay, T., Zhang, W. W., Owen-Schaub, L. B. and Roth, J. A. (1994) Induction of chemotherapy in human lung cancer cells in vivo by adenovirusmediate transfer of wild-type p53 gene. Cancer. Res. 54: 2287-91

Haapajarvi, T., Kivinen, L., Heiskanen, A., des Bordes, C., Datto, M. B., Wang, X. F. and Laiho, M. (1999) UV radiation is a transcriptional inducer of p21(Cip1/Waf1) cyclin-kinase inhibitor in a p53-independent manner. Exp. Cell. Res 248: $272-9$

Hale, A. J., Smith, C. A., Sutherland, L. C., Stoneamn, V. E., Longthorne, V. L., Culhane, A. C. and Williams, G. T. (1991) Apoptosis: molecule regulation of cell death. Eur. J. Biochem. 236: 49

Kim, J., Lee, S. K., Hwang E. S., Kim, J. S., Kim K. and Lee, J. H. (1997) Limited cytotoxic effect of adenoviral-mediated p53 gene transfer in variable non-small cell lung cancer (NSCLC) cell lines. J. Korean. Cancer. 29: 565-575

Lowe, S. W., Ruley, H. E., Jacks, T. and Housman, D. E. (1993) p53-dependent apoptosis modulates the cytotoxicity of anticancer agents. Cell. 74: 957-967

Levine, A. J. (1997) p53, the cellular gatekeeper for growth and division. Cell. 88: 323-331

Michael, W. (1998) Predicting reponse to cancer chemotherapy: the role of p53. Cell. Tissue. 292: 435-445

Mikhail, V. B., Paraskevi, G. and Malgorzata, W. (1998) Effects of p53-expressing adenovirus on the chemosensitivity and differentiation of anaplastic thyroid cancer cells. J. Clinical. Endocrinol \& Metabolism. 83: 2516-2522.

Miyashita, T., Krajewski. S., Krajewska, M., et al. (1994) Tumor suppressor p53 is a regulator of bcl-2 and bax gene expression in vitro and in vivo. Oncogene. 9: 1799-1809

Müller, $\mathrm{H}$ and Eppenberger, U. (1996) The dual role of mutant p53 protein in chemosensitivity of human cancer. Anticancer. Res. 16: 3845-3848

Nguyen, D. M., Spitz, F. R., Yen, N., Cristiano, R. J. and Roth, J. A. (1996) Gene therapy for lung cancer: enhancement of tumor suppression by a combination of sequential systemic cisplatin and adenovirus-mediated p53 gene transfer. J. Thorac. Cardiovasc. Surg. 112: 1372- 1377

Ogawa, N., Fujiwara, T., Kagawa, S., Nishizaki, M., Morimoto, Y., Tanida, T., Hizuta, A., Yasuda, T., Roth, J. A. and Tanaka, N. (1997) Novel combination therapy for human colon cancer with adenovirus-mediated wild-type p53 gene transfer and DNAdamaging chemotherapeutic agent. Int. J. Cancer. 73: 367-370

Perego, P., Giarola, M., Righetti, S. C., Supino, R., Caserini, C., Delia, D., Pierotti, M. A., Miyashita, T., Reed, J. C. and Zunino, F. (1996) Association between cisplatin resistance and mutation of p53 gene and reduced bax expression in ovarian carcinoma cell systems. Cancer Res 156: 556-62

Rusch, V., Klimstra, D. and Venkatraman, E. (1995) Aberrant p53 expression predicts clinical resistance to cisplatin-based chemotherapy in locally advanced non-small-cell lung cancer. Cancer Res. 55: 5038-5042

Ulisses, G. L., Peter, E., Ryoji, Y. and Geoffrey, M. C. (1997) p53-dependent induction of apoptosis by proteasome inhibitors. J. Biol. Chem. 272: 12893-12896

Wang, X., Liu, Y., Chow, L. S., Wong, S. C., Tsao, S. W., Kwong, D. L., Wang, J., Sham, J. S., Nicholls, J. M. (1999) Cisplatin-induced p53-independent growth arrest and cell death in cancer cells. Int. J. Oncol. 15: 1097-1102 